\title{
A refletância na estimativa do efeito de fungicidas no controle da ferrugem asiática da soja
}

\author{
Alexandre José da Silva ${ }^{1}$; Marcelo Giovanetti Canteri ${ }^{1}$; Débora Cristina Santiago ${ }^{1}$; Marceli Hikishima ${ }^{1}$; André Luiz \\ da Silva ${ }^{1}$.
}

${ }^{1}$ Departamento de Agronomia, UEL, Londrina, PR, 86051-990, aleagro62@hotmail.com.

*Autor para correspondência: Alexandre José da Silva

Data de chegada: 17/09/2007. Aceito para publicação em: 28/11/2008

1537

\section{RESUMO}

Silva, A. J. Da.., Canteri, M. G., Santiago, D. C., Hikishima, M., Silva, A. L. Da. A refletância na estimativa do efeito de fungicidas no controle da ferrugem asiática da soja. Summa Phytopathologica, v.35, n.1, p.53-56, 2009

Medidas de refletância têm apresentado resultados eficientes para avaliar a eficiência de fungicidas, além de ser um método prático e rápido. O objetivo do trabalho foi comparar medidas de refletância com o método de avaliação visual para avaliar a eficiência de fungicidas no controle da ferrugem asiática da soja e quantificar a relação com a produtividade. O ensaio foi instalado na Fazenda Escola da UEL, cv. BRS 133, em delineamento de blocos ao acaso com 07 diferentes fungicidas, em 04 repetições. Foram realizadas duas pulverizações, sendo a $1^{\circ}$ no estádio R2 (3\% de severidade) e a segunda em R5.1, 20 dias após. Avaliou-se visualmente a severidade de ferrugem asiática e calculou-se a área abaixo da curva de progresso da doença (AACPD).
Também, avaliou-se a produtividade final e a percentagem de radiação solar em $810 \mathrm{~nm}$ (R810) com o uso de radiômetro de multiespectro e calculou-se a área abaixo da curva de progresso da radiação (AACPR). O coeficiente de determinação $\left(R^{2}\right)$ para regressão entre as variáveis AACPD x produtividade foi 0,79 , entre AACPR x produtividade foi 0,90 e AACPD x AACPR foi 0,89. A utilização de refletância (R810) permitiu a separação dos tratamentos fungicidas em três grupos distintos, sendo epoxiconazol com menor eficiência, metconazol, tebuconazol e piraclostrobina + epoxiconazol foram classificados como intermediários e os mais eficientes foram, azoxistrobina + ciproconazol e picoxistrobina + ciproconazol.

Palavras-chave adicionais: fitopatometria, sensoriamento remoto, radiômetro de múltiplo espectro, Phakopsora pachyrhizi.

\section{ABSTRACT}

Silva, A. J. Da.., Canteri, M. G., Santiago, D. C., Hikishima, M., Silva, A. L. Da. The reflectance in the estimate of the effect of fungicides in the control of asian soybean rust. Summa Phytopathologica, v.35, n.1, p.53-56, 2009

Measurement of reflectance has been shown an efficient, pratical and quick method to evaluate the efficiency of fungicides, in disease control. The objective of the work was to compare the use of reflectance measurement with visual disease assessment method to evaluate the efficiency of fungicides for the controlling Asian soybean rust relating the assessment data with yield. The assay was carried out in the Farm School of UEL, with the soybean cV. BRS 133, in randomized block design with seven fungicide treatments and control without fungicide, four replicates. Two sprayings were applied at the $\mathrm{R}^{2}$ (3\% of severity) and R5.1, growth stages. Soybean rust severity was evaluated visually based on a rate scale and the percentage of solar radiation at $810 \mathrm{~nm}$ ( $\mathrm{R} 810)$, assessed with a multispecter radiometer. These data were use for stimating the area under of the disease progress curve (AACPD), and the area under of the curve of progress of the radiation (AACPR), respectively. The coefficient of determination $\left(\mathrm{R}^{2}\right)$ for regression between variables AACPD $\mathrm{x}$ productivity was 0,79 between AACPR x productivity was 0,90 and AACPD x AACPR was 0,89. The data had demonstrated that the measurement of reflectance use (R810) allowed the separation of the fungicide treatments in three distinct groups, being epoxiconazol with lesser efficiency, metconazol, tebuconazol and piraclostrobina + epoxiconazol classified as intermediate and azoxistrobina + ciproconazol and picoxistrobina + ciproconazol as the most efficient treatments.

Keywords: Phytopathometry, remote sensing, multispectral radiometer, Phakopsora pachyrhizi.

A soja é uma das culturas que vem garantindo a sustentabilidade econômica da atividade agrícola no Brasil. A sua área de cultivo aumenta ano após ano $(10,17)$, além de apresentar grande importância social e econômica, provendo mais de $64 \%$ do suprimento global de farelo de oleaginosas $(17,18)$.

Atualmente, a distribuição da Phakopsora pachyrhizi Syd. \& P. Syd inclui África, Ásia, Austrália, América e Havaí. A rápida dispersão e potencial para severas perdas de produção tornam a ferrugem a mais destrutiva doença foliar dentre as mais de uma centena que afetam a soja [Glycine max (L.) Merrill]. (10, 17, 18).

Após a sua constatação no Brasil na safra de 2000/01 $(17,18)$, muitos têm sido os estudos com o intuito de manejo e controle dessa doença. Segundo Reis \& Bresolin (15), os tratamentos fungicidas da parte aérea tem sido muito utilizados como principal ferramenta e tática de controle.

Trabalhos têm demonstrado a possibilidade de se usar medidas de refletância como método de avaliação da eficiência de tratamentos fungicidas (3, 4, 10, 11, 12, 13). Leituras de refletância realizadas com radiômetro de múltiplo espectro na faixa de comprimento de onda próximo ao infravermelho (11) apresentam uma boa correlação com o índice de área foliar verde (GLAI) e até mesmo com a área foliar fotossinteticamente ativa, presente por unidade de área de solo (4, 10, 11, 13). O GLAI pode ser afetado por fatores bióticos e abióticos, inclusive doenças $(12,13)$.

Diversos autores obtiveram bons resultados com o uso de radiômetro de múltiplo espectro na quantificação de doenças das 
culturas de feijão, amendoim, soja, batata inglesa, trigo e gramados. (3, 4, 6, 11, 12, 13).

Essa tecnologia apresenta algumas vantagens em relação aos métodos tradicionais, tais como: obtenção de informações sem que haja contato físico com o objeto, permitindo repetidas observações; leituras em uma faixa espectral não captada pelo olho humano; aumento na velocidade de aquisição dos dados, e redução do esforço de trabalho, pois se baseia nas propriedades radiantes das plantas $(3,4)$. As avaliações, nessa nova abordagem, são realizadas através de instrumentos capazes de quantificar as diferenças nas respostas espectrais entre a planta sadia e a doente.

O presente trabalho teve como objetivo comparar medidas de refletância com métodos de avaliação visual para avaliar a eficiência de fungicidas para o controle da ferrugem asiática da soja e quantificar a relação com a produtividade.

\section{MATERIAL E MÉTODOS}

O experimento foi conduzido na Fazenda Escola da Universidade Estadual de Londrina, Londrina - PR, na safra 2006/07, em delineamento de blocos ao acaso com sete tratamentos e quatro repetições. As dimensões foram 2,4 m de largura x $5 \mathrm{~m}$ de comprimento, totalizando $12 \mathrm{~m}^{2}$. A cultivar utilizada foi BRS 133 semeada em sistema de plantio direto, com espaçamento de $0,50 \mathrm{~m}$ entre linhas, apresentando 10 plantas/metro linear e uma população de 200 mil plantas por hectare. Duas linhas centrais da parcela para as avaliações e colheita do experimento (área colhida de $5 \mathrm{~m}^{2}$ ), descontando-se $0,50 \mathrm{~m}$ de bordadura. As aplicações de fungicidas foram feitas utilizando-se pulverizador costal pressurizado a $\mathrm{CO}_{2}$, contendo barra de 2,0 metros, quatro pontas jato plano do tipo XR 11002, espaçadas de $50 \mathrm{~cm}$, o volume a $200 \mathrm{~L} / \mathrm{ha}$, com pressão de 4 Bar. Os tratamentos, em gramas do ingrediente ativo/hectare foram: 1) testemunha (sem aplicação); 2) piraclostrobina + epoxiconazol (66,5 $+25)$; 3) azoxistrobina + ciproconazol $(60+24)$; 4) tebuconazol (100); 5) metconazol (36); 6) epoxiconazol (50); 7) picoxistrobina + ciproconazol $(120+120)$. A primeira aplicação foi realizada dia 27/ 02/2007, no estádio $R_{2}$ de acordo com Fehr \& Caviness (7), quando as plantas apresentavam em média $3 \%$ de severidade no terço inferior. A segunda aplicação ocorreu dia 17/03/2007 no estádio $\mathrm{R}_{5.1}$.

As avaliações de refletância (\% de luz solar refletida pelas plantas), foram realizadas por meio de sensoriamento remoto, no comprimento de onda próximo ao infravermelho $(810 \mathrm{~nm})$ utilizando um radiômetro portátil, multiespectro, marca CropScan Inc. $(12,13)$. As leituras foram realizadas aos 13, 21, 35 e 42 dias após a $1^{\circ}$ aplicação (DAA) em três áreas de $0,44 \mathrm{~m}^{2} /$ parcela. O aparelho captou os percentuais de refletância em diversos comprimentos de onda, via sensores que transformaram a quantidade de radiação incidente e refletida em valores de voltagem, a qual foi transformada posteriormente por um programa, em percentagem de refletância $(3,4)$. A severidade da ferrugem foi estimada semanalmente em quatro pontos de cada parcela, avaliando-se os terços inferior, médio e superior das plantas, iniciandose no estádio $\mathrm{R}_{3}$ e seguindo-se até a desfolha de $90 \%$ da testemunha. Utilizou-se escala diagramática para estimar a severidade da doença (9). Calculou-se a área abaixo da curva de progresso da doença (AACPD) de acordo com a equação apresentada por Shaner \& Finney (16). A produtividade e o peso de mil sementes foram avaliados ao final do ciclo da cultura em área correspondente a $5 \mathrm{~m}^{2}$. Os dados das avaliações foram submetidos à análise de variância pelo teste $\mathrm{F}$ e a diferença entre as médias, quando significativas, foram comparadas pelo teste de Skott Knott, a 5\% de probabilidade, usando-se o programa SASM-Agri (5). Também foram calculados os coeficientes de determinação da regressão entre as variáveis, severidade, AACPD, produção, e medidas de refletância obtidas nos respectivos tratamentos.

\section{RESULTADOS E DISCUSSÃO}

As medidas de refletância e o método de avaliação visual para severidade da doença foram eficazes na separação dos tratamentos fungicidas (Tabela 1). As medidas de refletância da luz solar em $810 \mathrm{~nm}$ e a AACPD foram mais eficientes para captar pequenas diferenças, separando os produtos em 03 grupos distintos. De acordo com as medidas de refletância, os produtos 2, 3, 4 e 7, constituiram o grupo 1 (G1) com maior eficiência, seguido pelo tratamento 5 (G2, intermediário) e tratamento 6 (G3) com menor eficiência. Os dados de AACPD permitiram a separação dos produtos 3 e 7 (G1); 2, 4 e 5 (G2) e 6 (G3), conforme mostrado na Tabela 1. A avaliação de severidade da doença aos 21 DAA possibilitou somente a separação dos tratamentos em dois grupos segundo sua eficiência (G1: 3 e 7) e (G2: 2, 4, 5 e 6 ).
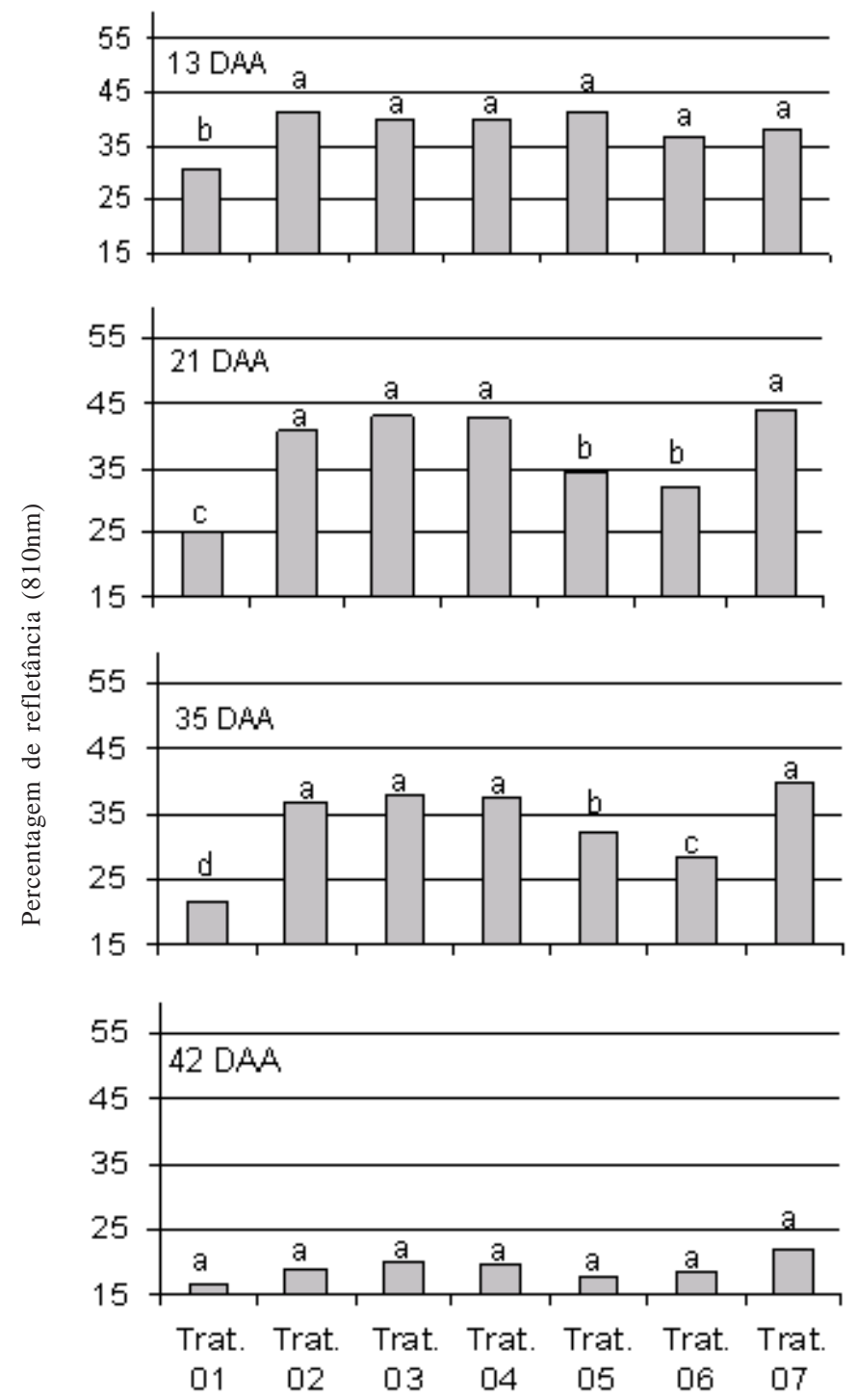

Figura 1. Percentagem de refletância da luz solar na faixa do infravermelho (810 nm) para plantas de soja tratadas com diferentes fungicidas para controlar a ferrugem da soja em quatro épocas de avaliação 13, 21, 35 e 42 DAA em 07 tratamentos com fungicidas, Londrina, Pr. 
Tabela 1. Área sob a curva de progresso da doença (AACPD), produtividade e medidas de refletância observadas em tratamentos fungicidas para o controle da ferrugem asiática.

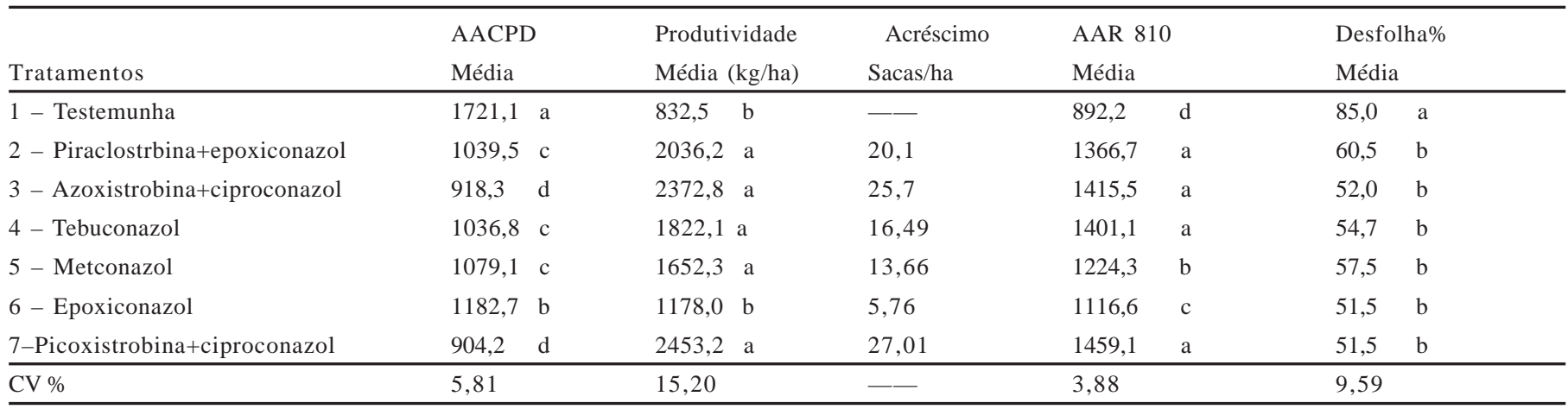

AACPD: Área abaixo da curva corrigida; AAR 810: Área abaixo da radiação; Médias seguidas de mesma letra não diferem estatisticamente entre si pelo teste de Skott knott (P<0,05).

O coeficiente de variação (CV) obtido para análise de regressão da severidade de ferrugem da soja aos 21 DAA foi 5,81 \%, enquanto o CV obtido na análise para a avaliação de refletância na faixa de $810 \mathrm{~nm}$ aos 21 DAA foi 3,88\% (Tabela 1). A maior eficiência obtida para as leituras de medidas de refletância pode ser explicada pelo menor CV associado ao tamanho da amostragem, pois a área amostrada foi de 0,88 $\mathrm{m}^{2}$, o que correspondia a mais de $20 \%$ da área útil das parcelas. Para as avaliações de severidade, utilizou-se uma amostra de 12 trifólios/parcela.

O tempo gasto foi em média duas horas para cada uma das avaliações de severidade de doença no ensaio. Nas leituras de refletância, gastaram-se em média 15 minutos. Como foram realizadas cinco avaliações, o tempo gasto foi de 10 horas para as avaliações visuais e uma hora e 15 minutos com o uso do radiômetro. Segundo Canteri et al., $(4,6)$, além de demandar mais tempo e ser uma atividade laboriosa, pode incorrer de erros de anotação e transcrição, além da subjetividade humana na interpretação da severidade da doença.

As leituras de refletância a $810 \mathrm{~nm}$ apresentaram resultados inversamente proporcionais às avaliações de severidade das doenças (Tabela 1). Comprimentos de onda próximos ao infravermelho, onde se inclui a faixa de $810 \mathrm{~nm}$ apresentam boa correlação com quantidade de tecido vegetal vivo $(8,12,14)$. De acordo com Canteri et al. (4) as medidas de refletância na faixa de $810 \mathrm{~nm}$ são na verdade estimativas de área foliar sadia, a qual é diretamente responsável pela fotossíntese para enchimento dos grãos.

Os dados da Figura 1 demonstram o comportamento da refletância em $810 \mathrm{~nm}$ para os tratamentos em função do tempo. Aos 13 DAA não foi possível a diferenciação da eficiência dos tratamentos fungicidas, mesmo antes de ter sido realizada a segunda aplicação. As leituras realizadas aos 21 e 35 DAA, após as duas aplicações, foram mais eficientes em separar os tratamentos. Já na última leitura (42 DAA) não houve separação entre os tratamentos, fato que pode ser explicado pela desfolha ocasionada pela doença. A média de refletância da luz solar em $810 \mathrm{~nm}$, para todos os tratamentos, foi 38,1 aos 13 DAA, caiu para 37,0 aos 21 DAA; 33,2 aos 35 DAA e 19,1 aos 42 DAA.

Analisando-se os dados de produtividade (Tabela 1), que é uma variável importante para representar a eficiência de fungicidas (1) observou-se que houve separação entre os tratamentos fungicidas, sendo os tratamentos 2, 3, 4, 5 e 7 superiores ao tratamento 6. A análise de regressão entre a produtividade e as demais variáveis indicou que a avaliação executada aos 21 DAA apresentou melhores resultados (Figura 2). O coeficiente de determinação $\left(R^{2}\right)$ para relação entre produtividade e refletância foi maior (89\%), enquanto que para

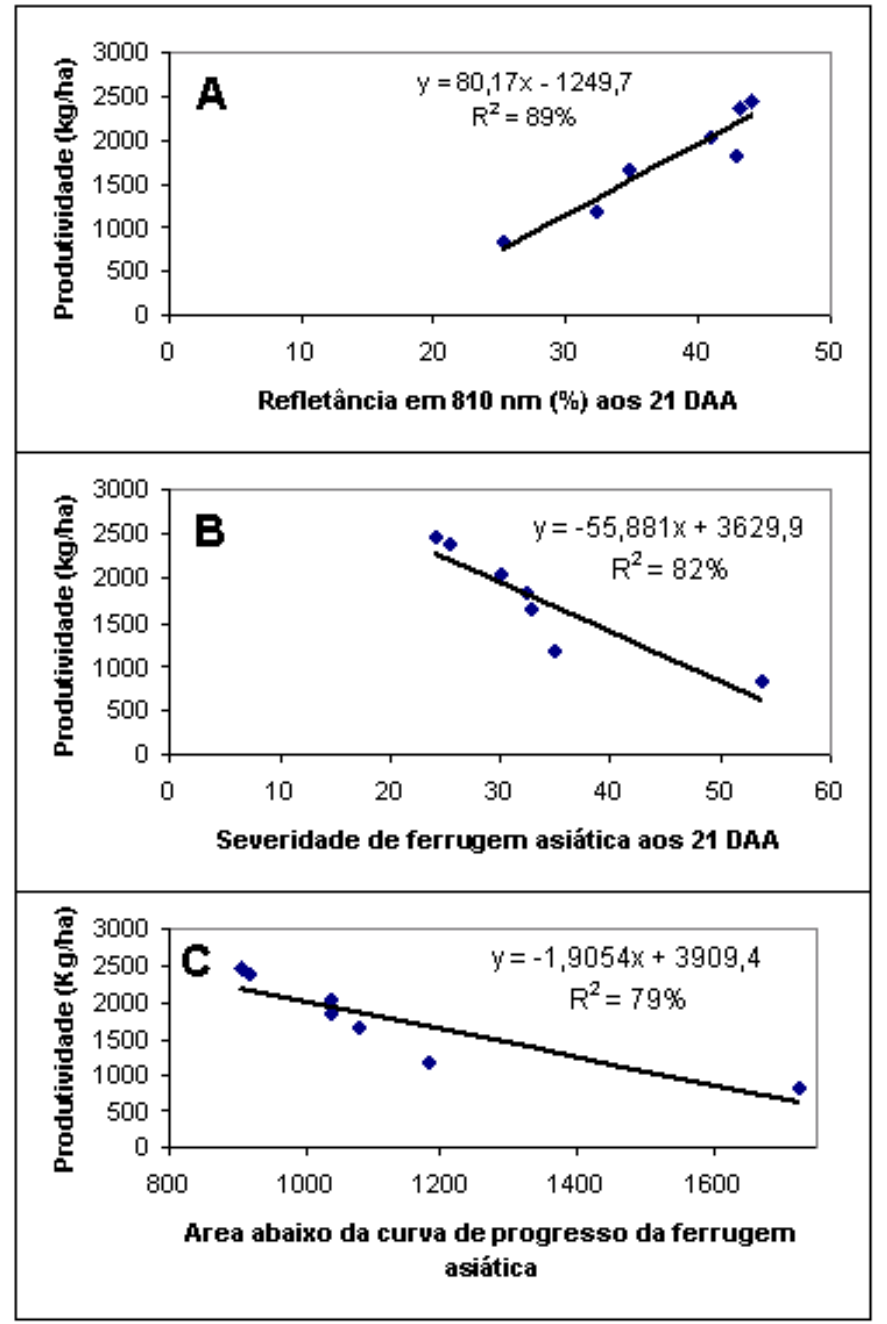

Figura 2. Relações entre produtividade e refletância da luz solar em 810 $\mathrm{nm}$ aos 21 DAA (A), percentagem de severidade de ferrugem asiática avaliadas aos 21 DAA (B), área sob a curva de progresso da ferrugem asiática (C), para soja tratada com diferentes fungicidas, Londrina, PR.

produtividade e severidade foi de $82 \%$. Com o uso da AACPD no lugar da severidade, não houve melhora no valor de $\mathrm{R}^{2}$ (79\%).

A variável AACPD é recomendada por autores para representar a epidemia como um todo (16). Utiliza as avaliações visuais de severidade 
para o seu cálculo e geralmente apresenta boa correlação com a produtividade (3). De acordo com a Figura 2, a AACPD apresentou alta correlação com a produtividade (79\%), porém, a R810 realizada aos 21 DAA apresentou o maior valor (89\%). A explicação para a melhor correlação entre medidas de refletância e produtividade é que a produtividade está relacionada à quantidade de radiação interceptada pela cultura $(1,9,19)$ e a refletância correlaciona com quantidade de tecido foliar fotossinteticamente ativo presente por unidade de área capaz de interceptar a radiação solar $(1,9,11)$, diferentemente de avaliações de percentagem de severidade de doença que medem a quantidade de tecido doente (4).

Os tratamentos com azoxistrobina + ciproconazol e picoxistrobina + ciproconazol apresentaram menores valores de AACPD (Tabela 1), sendo estatisticamente superiores à testemunha e aos demais tratamentos.

As medidas de refletância em R810 apresentaram correlação com produtividade e severidade. Mesmo sendo um método indireto de avaliação de severidade de doenças, ou seja, não avalia a severidade de doença, mas sim apresenta correlação com o índice de área foliar da cultura (4). No entanto, falhas no plantio, problemas com população de plantas ou com ervas daninhas podem interferir nas leituras. Plantas protegidas com fungicidas, geralmente apresentam folhas sadias, verdes que proporcionam maior índice de refletância.

O uso de medidas de refletância em $810 \mathrm{~nm}$ para avaliar eficiência de fungicidas contra ferrugem asiática em soja mostrou-se um método rápido, com alta correlação com produtividade e com o menor coeficiente de variação entre os métodos de avaliação em teste. Apresentou potencial para ser utilizado também para detecção de efeitos fitotóxicos ou tônicos dos fungicidas que além de controlar a doença, pode impedir ou favorecer o crescimento satisfatório das plantas.

Para o patossistema Phakopsora pachyrhizi-soja, na safra 2006/ 07, o uso de medidas de refletância mostrou-se viável e eficiente para avaliação da eficiência de fungicidas.

\section{REFERÊNCIAS BIBLIOGRÁFICAS}

1. Bergamin Filho, A., Lopes, D.B., Amorim, L., Godoy, C.V., Berger, R.D. Avaliação de danos causados por doenças de plantas. Revisão Anual de Patologia de Plantas, Passo Fundo, v.3, p.133-184, 1995.

2. Bromfield, K.R. Soybean rust. Some considerations relevant to threat analysis. Monograph. Protection Ecology v.2, n.3, p.251257, 1980.

3. Canteri, M.G. Uso de medidas da área foliar sadia e refletância no manejo da mancha angular do feijoeiro. 1998. 81 p. Tese. (Doutorado em Agronomia) - Escola Superior de Agricultura "Luiz de Queiroz”, Universidade de São Paulo, SP.
4. Canteri, M.G., Vitti, A.J., Amorim, L., Bergamin Filho, A. Refletância e avaliação visual como indicadores de severidade de doenças foliares comparados à produtividade do amendoim. Summa Phytopathologica, v.25, n.3. p.228-233, 1999.

5. Canteri, M. G.; Althaus, R.A.; Virgens Filho, J.S.; Giglioli, E.A.; Godoy, C.V. SASM-Agri: Sistema para análise e separação de médias em experimentos agrícolas pelos métodos Scott-Knott, Tukey e Duncan. Revista Brasileira de Agrocomputação, v.1, n.2, p.18-24, 2001.

6. Canteri, M.G., Dalla Pria, M., Amorim, L., Bergamin Filho, A. Uso de radiômetro de múltiplo espectro na avaliação de fungicidas para controle de ferrugem do feijoeiro. In: Congresso Brasileiro de Fitopatologia. 29, p.350. Campo Grande. Resumos... Brasília: Sociedade Brasileira de Fitopatologia, 1996.

7. Fehr, W.R.; Caviness, C. E. Stages of soybean development. Ames: Iowa State University, Cooperative Extension Service, 11p., Special Report, 1977.

8. Gaunt, R.E. The relationship between plant disease severity and yield. Annu. Rev. Phytopathol. Palo Alto, v.33, p.119-144, 1995b.

9. Godoy, C.V.; Koga, L. J.; Canteri, M.G.. Diagrammatic scale for assessment of soybean rust severity. Fitopatologia Brasileira. 31:063-068. 2006.

10. Juliatti, F.C.; Polizel, A.C.; Juliatti, A.C.; Manejo Integrado de Doenças na Cultura da soja. Uberlândia: UFU. 2004, 327p.

11. Nilsson, H.E. Remote sensing and image analysis in plant pathology. Canadian Journal of Plant Pathology. Ottawa, v.17, p.154-166, 1995.

12. Nutter, F.W.Jr., Detection and measurement of plant disease gradients in peanut with a multispectral radiometer. Phytopathology. St. Paul, v.79, n.9, p.958-963, 1989.

13. Nutter, F.W.JR., Littrel, R.H. Relationships between defoliation, canopy reflectance and pod yield in the peanut-late leafspot pathosystem. Crop Protection, Guilford, v. 15, n.2, p.135-142, 1996.

14. Nutter, F.W. JR., Littrel, R.H., Brenneman, T.B. Utilization of a multispectral radiometer to evaluate fungicide efficacy to control late leaf spot in peanut. Phytopathology. St. Paul, v.80, n.1, p.102-108, 1990.

15. Reis, E. M.; Bresolin, A.C.R. Fatores climáticos e doenças de plantas. In: Reis, E. M. Previsão de doenças de plantas. Passo Fundo, R.S. Universidade de Passo Fundo. 2004. P. 23-45.

16. Shaner, G.; Finney, R. F. The effects of nitrogen fertilization on the expression of show-mildwing in knox wheat. Phytopathology, v. 67, p. $1051-1055,1977$.

17. Tecnologias de Produção. Região Central do Brasil - 2005. Tecnologias de produção de soja - 2005. Londrina: Embrapa Soja: Embrapa Cerrados: Embrapa Agropecuária Oeste: Fundação Meridional, 2004. 239p.

18. Yorinori, J.T.; Junior, J.N.; Lazzaroto, J.J. Ferrugem "asiática" da soja no Brasil: evolução, importância econômica e controle. Londrina: Embrapa Soja. Documentos $\mathbf{n}^{0}$. 247, 2004, 36p.

19. Waggoner, P.E., Berger, R.D. Defoliation, disease, and growth. Phytopathology. St. Paul, v.77, p.393-398, 1987. 